\section{A fermentação culfural da década brasileira de 60}

\section{RESUMO}

A principal característica da década de 60 é a contradição. Ela se expressa através de variadas e múltiplas posições em todos os campos da atividade política, econômica e cultural. Este ensaio aborda o conjunto dessas especificidades que constituíram um dos mais ricos e paradoxais períodos da história brasileira contemporânea.

\section{ABSTRACT}

In Brazil, many activities within the field of politics, economics and culture typify the 1960's as a decade of contradiction. So the aim of this article is to approach this period of the Brazilian contemporary history in order to show the cultural ferment.

\section{AntônioHohlfeldt}

Doutor em Teoria da Literatura pela PUCRS.

Coordenador do Programa de Pós-Graduação em

Comunicação Social, da FAMECOS-PUCRS.
Nós fomos uma geração que quisemos ter acesso à cultura.

Vera Sílvia Magalhães in "Estrangeira em seu próprio país", Revista de Cultura Vozes, No.1, Ano 92, Vol. 92,

p.111.

A PRINCIPAL CARACTERÍsTICA da década de 60 é a contradição. Ela se expressa através de variadas e múltiplas posições em todos os campos da atividade política, econômica e cultural. Daí a perspectiva de oposição entre diferentes princípios e ideologias, que acaba se expressando numa tensão constante. De um lado, o corte com a tradição. De outro, a retomada dessa mesma tradição. Ideologicamente, nada melhor para expressar este princípio do que a conhecida imagem do General Golbery do Couto e Silva que, embora aplicada a um outro contexto, expressa com absoluta fidelidade o que vivemos naquela década: os movimentos de sístole e diástole ${ }^{1}$. Havia, efetivamente, uma vontade de abertura para o mundo e, ao mesmo tempo, um voltar-se para dentro de si mesmo.

Em 21 de abril de 1960 inaugurara-se Brasília, a nova capital brasileira. O slogan de Juscelino Kubitschek era significativo: 50 anos em 5. O desenvolvimentismo afirmava-se no Brasil a partir daquele desafio concretizado. Logo em 1964, contudo, a nação sofreria um golpe de estado. $\mathrm{O}$ interregno destes quatro anos ilustra, à saciedade, as contradições e as tensões vividas pela nação.

$\mathrm{Na}$ verdade, este tensionamento não era novo. Pelo menos desde as décadas de 10 e 20 ele se colocava em especial para os intelectuais e os políticos brasileiros, como bem relembra Celso Furtado: ${ }^{2}$ em 1922 tivéramos a Semana de Arte Moderna em São Paulo, mas em 1928 Paulo Prado editaria o pessimista Retrato do Brasil. De um lado, Mário de Andrade fizera a descoberta do Brasil a partir da cultura popular e da Amazônia, mas pouco antes Oliveira Vianna decretara a ideologia conservadora e militarista expressa especialmente em Popula- 
ções meridionais do Brasil (1920). Em 1924 descobríramos o antropofagismo oswaldiano, mas em 1937 sofreríamos o intervencionismo do Estado Novo.

Carlos Guilherme Motta, em Ideologia da cultura brasileira, ${ }^{3}$ divide em três épocas distintas a história brasileira recente (considerando o período por ele estudado): a) de 1957 a 1964, ampliação e revisão reformistas; b) de 1964 a 1969, revisões radicais; c) de 1969 a 1974, impasses da dependência. Complementarmente, Anamaria Fadul, com pequenas diferenças, admite quatro diferentes momentos em nossa história recente $^{4}$ : a) 1964 a 1968, do golpe militar ao AI-5; b) 1968 a 1974, do AI-5 até a posse do General Geisel; c) 1974 a 1979, da posse de Geisel à posse do General Figueiredo; d) período de Figueiredo à anunciada posse de Tancredo Neves.

Numa ou noutra divisão, verificamos que o mesmo movimento de composição e decomposição pode ser claramente observado. Como se disse, este movimento era verificável desde muito antes, embora ele vá se clarificando à medida em que avançamos no tempo (tomando como referencial o golpe de 1964).

Na década de 50, o país buscara configurar alguns horizontes de desenvolvimento científico bastante significativos: em 1951 criara-se o CNPq - Conselho Nacional de Pesquisa Científica, simultâneo ao surgimento da CAPES- Coordenação de Aperfeiçoamento de Pessoal de Nível Superior. A reforma universitária, desdobrada a partir de 1965, através do execrado acordo MECUSAID pode ser vista, ao mesmo tempo, como uma continuidade e uma ruptura em relação àquela primeira tendência, eis que, de um lado, tende a abandonar o enfoque humanista de nossa educação, buscando a formação profissionalizante e tecnicista, mas, ao mesmo tempo, propiciará o surgimento de nossos primeiros cursos de pósgraduação.

Da mesma maneira, assistimos, no âmbito da administração Juscelino Kubitschek, o surgimento, em 1956, e a solidifica- ção do ISEB - Instituto Superior de Estudos Brasileiros, idealizado e concretizado por um conjunto de militares ${ }^{5}$ claramente ligados aos tenentes dos anos 20. A ideologia nacionalista destes intelectuais não impediu que o governo JK se constituísse no primeiro grande momento de internacionalização de nossa economia, inclusive mediante a substituição de importações pela industrialização acelerada do país, a partir da instalação das montadoras de automóveis.

O período JK se caracteriza por uma internacionalização da economia brasileira justamente no momento em que se procura "fabricar" um ideário nacionalista para se diagnosticar e agir sobre os problemas nacionais. ${ }^{6}$

Assim, a contradição se apresenta num tensionamento em que o ISEB pretende influenciar o governo, enquanto este busca uma legitimação através do ISEB. A crise surgida já ao final daquela administração é bastante conhecida, estendendo-se ao longo do período seguinte, até a dissolução da instituição após o golpe de $1964 .^{7}$

Se a industrialização recebe forte impulso do governo, o segmento agrário, ao mesmo tempo, organiza-se para a sua luta, criando-se, a partir de 1955, a primeira Liga Camponesa, sediada no Engenho Galiléia, ${ }^{8}$ culminando com a I Conferência de Lavradores e Trabalhadores Agrícolas Brasileiros, em Belo Horizonte, em novembro de 1962. A reforma agrária seria incluída nas reformas de base, mas o primeiro documento importante sobre o tema seria produzido apenas no período do General Castello Branco, após o golpe de 1964.

Por outro lado, a cultura alienada, a que mais tarde referir-se-á o CPC-Centro Popular de Cultura da UNE, entra em discussão. A "ideologia nacionalista queria ser o idioma político dominante". ${ }^{9}$ Ao longo dos anos 50, construíra-se uma espécie de onipotência da intelectualidade, que sentia uma vocação para conduzir os destinos da nação, ainda segundo o brazilianist francês (p. 114), sentimento que seria seguido de outro, absolutamente oposto, o da precarie- 
dade de sua própria subsistência, após o golpe de 1964 e, em especial, após o AI-5 de dezembro de 1968. Uma síntese precária adviria com a organização dos cursos de pós-graduação nas universidades, às quais se confinariam os intelectuais, enquanto professores, não sem sofrerem controles ideológicos e processos de cassação, como os verificados logo após o AI-5. De qualquer forma, eles se tornariam profissionais e especialistas, limitando-se, parcialmente, a um papel bem menos vanguardista do que haviam pretendido antes.

$\mathrm{Na}$ verdade, ao ISEB opor-se-ia o IBAD - Instituto Brasileiro de Ação Democrática, fundado em 1959, com cobertura direta da CIA, e que se desdobraria ainda no IPES- Instituto de Pesquisas e Estudos Sociais, de 1961, também apoiado pelos norteamericanos, quando a ascensão inevitável de João Goulart vinha radicalizar o tensionamento entre o pensamento nacionalista e o internacionalista. ${ }^{10}$

É importante lembrar-se que os acontecimentos brasileiros integravam-se a um contexto internacional, e especialmente latino-americano igualmente contraditório: em 1959 ocorrera a revolução cubana liderada por Fidel Castro, o que fizera com que os Estados Unidos voltassem seus olhares mais diretamente para o continente, resultando na criação, em 1961, da Aliança para o Progresso.

Os debates que se sucediam no continente equilibravam-se entre a teoria $d a d e-$ pendência e o desenvolvimentismo. Assim, ao nacionalismo exacerbado, complementado pelo pan-americanismo que se tornará evidente no Brasil durante o período de Jânio Quadros, por exemplo, opõe-se um internacionalismo crescente. Contra o localismo defende-se o cosmopolitismo, ${ }^{11}$ ao ufanismo opõe-se o criticismo, entendendo-se a necessidade de um ponto de ruptura que se oriente, simultaneamente, pelo nacional e o popular, apontando, ao mesmo tempo, para uma ampliação da experiência democrática ( o que se fará nos turbulentos anos da administração de João Goulart, sobretudo após o plebiscito de janeiro de 1963), mas resultando na concretização ditatorial do golpe de março de 1964.

Quatro conceitos centralizam os debates: povo - nação - Estado e revolução, ${ }^{12}$ dividindo-se, o último, entre a utopia socialista e a reforma democrático-burguesa. As contradições ficam especialmente evidentes quando se examina, já há distância, o conhecido Manifesto do CPC, assinado, dentre outros, por Carlos Estevam Martins. Pretende-se falar em nome do povo e em defesa do povo, mas o texto se dirige o tempo todo aos intelectuais e aos artistas, especialmente aqueles a quem se considera alienados, ${ }^{13}$ numa espécie de chamamento à conscientização e ao engajamento.

A modernização convivia com o arcaís$m o,{ }^{14}$ da mesma maneira que o ideologismo com o esteticismo na produção artística daquele período. De um lado, aspirava-se à assimilação cultural, de outro, à explicitação dos conflitos e das contradições. ${ }^{15}$

Era consensual, contudo, entre as diferentes correntes ideológicas, que uma solução deveria ocorrer. A esquerda nacionalista tratou de pressionar cada vez mais o governo João Goulart em direção às reformas de base. Os conservadores, por outro lado, organizaram-se, fartamente financiados através da CIA, nas manobras que resultariam no golpe de 1964. O desenlace, uma vez mais, apresenta-se contraditório: pode ser visto enquanto a ruptura com a tendência nacionalista e populista, na medida em que a ditadura modificaria profundamente $o$ espaço de interferência tanto da intelectualidade quanto dos segmentos sindicais e religiosos brasileiros. No entanto, se visualizado em relação à década de 50, nada mais faz do que retomar, expandir e aprofundar a industrialização e a internacionalização, através de acordos bilaterais e de um conjunto de medidas político-administrativas que, até 1968, terá modificado significativamente o país, possibilitando o surgimento do que verdadeiramente se poderá desde então denominar como indústria cultural enquanto um livre mercado ${ }^{16}$ anima- 
do, protegido e articulado através do Estado, na medida em que a forma produtiva é acionada pela motivação econômica do retorno do capital, o lucro (p. 140), cujas conseqüências são, no mínimo, três: dutos;

a) superabundância de oferta de pro-

b) ilusão da transformação do real;

c) reconhecimento autoritário da validade de sua própria produção, pela aceitação tautológica do mercado (p.142).

Evidentemente, cada campo artístico desenvolverá seus próprios mecanismos, contando inclusive com a explosão da atividade publicitária que "assumiu uma função econômica fundamental na implementação do modelo de desenvolvimento adotado". ${ }^{17} \mathrm{O}$ mercado de consumo brasileiro é caracterizado por sua enorme dimensão, mesmo que se considere o relativamente pequeno percentual da população capaz de absorver os novos produtos de consumo que se lançarão. Trata-se de um conjunto diferenciado e cada vez mais amplo, que justifica o projeto de integração nacional que, a partir de então, será concretizado, através da EMBRATEL - Empresa Brasileira de Telecomunicações, constituída enquanto empresa pública a partir de 16 de setembro de 1965. A nova empresa desenvolve uma fantástica rede de torres de retransmissão, ligadas a um satélite de comunicações, enquanto, em conjunto com as empresas privadas, e mediante a política de concessões e revisão das mesmas, criam-se as redes nacionais de televisão e os grandes conglomerados de comunicações, colocando em mãos de um grupo selecionado de empresários emissoras de rádio e televisão, bem como grandes empreendimentos de jornalismo gráfico, de que emergirão grupos como a Abril Cultural ou a TV Globo. A iniciativa se completa com a criação, a 15 de janeiro de 1968, da AERP - Assessoria Especial de Relações Públicas da Presidência da República, que logo se tornaria o maior anunciante do país. ${ }^{18}$

Neste episódio, uma vez mais, a contradição é evidente. De um lado, deve-se levar em conta que fora o governo João Goulart que, através da lei n. ${ }^{\circ} 4.117$, de 27 de agosto de 1962, editara o Código Brasileiro de Telecomunicações e criara o CONTEL - Conselho Nacional de Telecomunicações, buscando a institucionalização do novo Código Brasileiro de Comunicações a partir de 1962, a que se seguiria a regulamentação do mesmo Código em 20 de março de 1963, atualizando-se a regulamentação dos serviços de radiodifusão em 31 de outubro daquele ano. No entanto, a colocação em prática dessas determinações, evidentemente adaptadas à ideologia do novo poder, dar-se-ia apenas após 31 de março de 1964. Por outro lado, os grupos empresariais brasileiros interessados em ampliar sua presença no novo campo das comunicações tomara iniciativas desde muito antes: já em 18 setembro de 1950, Assis Chateaubriand e os Diários e Emissoras Associados haviam investido no novo meio de comunicação que era a televisão, com a inauguração da TV Difusora, mais tarde TV Tupi, canal 3, em São Paulo e, logo em seguida, no Rio de Janeiro. Em 1953, surgiria a TV Record do Rio de Janeiro. Outros países da América Latina inaugurariam seus sistemas comerciais de televisão na mesma década: a Venezuela a partir de 1955 e o Uruguai em 1956, sendo o sistema argentino deste mesmo ano.

Em 1962, a TV Globo firma o acordo, depois cancelado, com o grupo norte-americano Time-Life, o que lhe daria não apenas um significativo aporte financeiro quanto permitir-lhe-ia um salto qualitativo na tecnologia empregada para as transmissões, o que a transformaria, imediatamente, no principal adversário do grupo das emissoras Associadas. Naquele mesmo ano de 1962, criava-se a ABERT - Associação Brasileira de Emissoras de Rádio e Televisão, como resposta dos empresários ${ }^{19}$ que detinham as concessões governamentais, à crescente presença e pressão governamental naquele campo de atividade, sempre mais e mais regulamentada pelo Estado.

Os Estados Unidos, por outro lado, a 
partir de agosto de 1962, aprovam a Lei do Satélite de Comunicações, que permite que se considere como de interesse governamental iniciativas de empresas particulares neste novo campo tecnológico, ampliando sua presença e predomínio internacional em fevereiro de 1963, com a criação do COMSAT - Communications Satelitte Corporation e, em 20 de agosto de 1964, do INTELSAT - International Communications Satelitte Consortium, englobando países europeus e latino-americanos enquanto potenciais clientes para seus satélites de comunicações. ${ }^{20} \mathrm{O}$ Brasil associar-se-ia ao consórcio em 4 de fevereiro de 1965 e a 25 de fevereiro de 1967 cria o Ministério das Comunicações, por decreto-lei.

Temos, assim, iniciativas norte-americanas no desenvolvimento de tecnologias de ponta, ao mesmo tempo em que outras, inéditas no Brasil, são aqui implantadas, ainda no decorrer da administração João Goulart. Quando se dá a ruptura institucional, os novos governantes encontram disponibilizadas as tecnologias de que necessitam para concretizar o controle ideológico sob a capa do discurso da integração nacional: o sistema de torres de retransmissão, a discagem direta à distância e os satélites de comunicação permitem que aqueles concessionários de rádio e televisão, considerados confiáveis pelo sistema, possam ampliar sua presença, viabilizados, simultaneamente, pelo desenvolvimento da infra-estrutura tecnológica, a cargo do governo, e pela expansão do mercado de consumo, ampliado pela incrementação da atividade publicitária, já organizado em redes regionais, e logo depois nacionais.

Se as primeiras telenovelas haviam surgido, através da TV Excelsior e Tupi, logo seguidas pelos shows musicais da Excelsior, em 1965 seria a vez do jornalismo, com o Telejornal da TV Globo. No ano de 1967 atingir-se-ia o auge da programação musical, com programas como Jovem Guarda, O Fino da Bossa e os festivais de música popular brasileira, em especial através da TV Record. A contradição, con- tudo, perdura: de um lado, compositores e intérpretes como Chico Buarque de Holanda e Gilberto Gil encontram intérpretes como Elis Regina e Jair Rodrigues, com linhas que se equilibram entre o poético e o militante. De outro, Caetano Veloso rompe as barreiras mais tradicionais de nossa música popular, estabelecidas desde 1956, com a bossa nova de João Gilberto, abrindo caminho para o Tropicalismo, a partir de 1968, após o sucesso da canção Alegria, alegria.

Neste mesmo ano de 1968, a disputa pelos mercados televisivos cresceria, com a presença do telejornalismo da Bandeirantes, através do Titulares da Notícia, respondendo a TV Globo com o incremento qualitativo de suas telenovelas, por exemplo, através das emissões de Os Irmãos Coragem. O surgimento do vídeo tape, em 1969, possibilitaria o Jornal Nacional da TV Globo, a $1^{\circ}$ de setembro, ampliando-se sua qualificação com a chegada da cor, em $1972,{ }^{21}$ o que completaria a revolução, solidificada desde 1967, com a implantação do primeiro satélite brasileiro de telecomunicações, ${ }^{22}$ no chamado padrão Globo de qualidade. A morte de Assis Chateaubriand, o incontestável líder das Associadas, em 1967 é, neste sentido, emblemática. A partir de então, cresce a estrela do conglomerado de Roberto Marinho, culminando o processo de transposição do controle das telecomunicações de um grupo ao outro, com a nãorenovação da concessão da TV Tupi e, logo em seguida, a idêntica medida com outras empresas do grupo Associado, que será redistribuído, resultando em novas redes como o SBT de Sílvio Santos: ${ }^{23}$ atingia-se, verdadeiramente, a integração nacional. ${ }^{24}$

\section{II}

Se a televisão apresenta, em sua implantação, as mesmas contradições que os demais sistemas culturais brasileiros, será ela, talvez, o único sistema, no entanto, que se manterá em relativa unidade ao longo dos 
anos 60. É que todos os demais segmentos da produção cultural do país, do teatro à música popular, passando pela literatura e as artes plásticas, sem esquecermos o cinema, estarão marcados pelo mesmo tensionamento que indicamos na abertura deste texto. Na verdade, enquanto parte da superestrutura produtiva, estes segmentos refletem e concretizam aquelas contradições que a sociedade brasileira evidenciava.

Literatura - Apesar do alto grau de analfabetismo, a literatura sempre teve um privilegiado status no país. ${ }^{25}$ Nossos escritores experimentaram forte influência sobre o pensamento nacional, provavelmente porque desenvolviam, paralelamente à produção mais estritamente literária, uma atividade jornalística, de que o sucesso de público da crônica melhor traduz esta situação. Aliás, é exatamente no decorrer dos anos 60 que este produto, simultaneamente literário e jornalístico, recebe a consagração dos leitores, com nomes como Otto Lara Rezende, Carlos Drummond de Andrade, Paulo Mendes Campos, Rubem Braga e outros tantos. Desde os revolucionários de 1922, a poesia brasileira oscilava entre a militância e o esteticismo, dividindo-se, por isso mesmo, pedagogicamente, as diferentes gerações segundo estes mesmos critérios: o experimentalismo de 22 se opõe, de certo modo, à crescente consciência social de 30, abrindo caminho para uma espécie de síntese que se esboça com a geração de 45, de que João Cabral de Melo Neto seria o exemplo mais significativo. Mas o tensionamento entre as diferentes tendências não se havia esgotado: em 1956 surge o Manifesto Concreto, liderado pelos irmãos Campos, complementado no ano seguinte pelo grupo Tendência, de Belo Horizonte, de Affonso Ávila. 1961 marca o manifesto do Poema Práxis, de Mário Chamie, mas em 1962 editam-se os três cadernos da coleção Violão de Rua, que se opunha a todas aquelas tendências, reunindo, dentre outros, a poetas como Ferreira Gullar e Moacyr Félix. ${ }^{26}$
Quanto à prosa, o chamado romance de 30 , essencialmente rural, com o ciclo de autores nordestinos, ganharia conotações urbanas com o grupo sulino, em especial Erico Verissimo e Dyonélio Machado. Na década de 60, passaria a sofrer o tensionamento de um experimentalismo crescente ao lado de um conjunto de obras claramente engajadas na denúncia do projeto ditatorial então em desenvolvimento, valendo citar, como exemplos, do primeiro grupo, a Wally Salomão (Me segura que eu vou dar um troço) e José Agrippino de Paula (Pan América) e, do outro, o Quarup de Antonio Callado. ${ }^{27}$ Gradualmente, as duas tendências encontrar-se-ão pela necessidade de driblar a censura e a proibição de livros, utilizando-se da técnica do romance reportagem exemplificados em Ivan Angelo e Ignácio de Loyola Brandão, dentre outros. O produto final desta época, por seu lado, gerará igualmente contraditórias avaliações com o passar do tempo. Flora Sussekind entende como francamente dispersiva aquela produção, ${ }^{28}$ enquanto Antonio Candido tem um entendimento contrário. ${ }^{29}$

Ao mesmo tempo, um sem-número de iniciativas alternativas vão se desdobrar: a poesia reproduzida em mimeógrafo, movimentos como o varal de poesia ou a chuva de poesia, a poesia-postal, e assim por diante, produções manifestamente artesanais, opunham-se às obras produzidas editorialmente em empresas que haviam sofrido forte modernização de seus parques gráficos no decorrer da década, como o caso exemplar da Record.

Teatro - Também o teatro vai experimentar este tensionamento. Desde 1948, a produção teatral brasileira experimentava uma qualificação crescente, com a inclusão à dramaturgia internacional de novos dramaturgos brasileiros e uma mise-en-scène relativamente atualizada à encenação européia, graças ao TBC - Teatro Brasileiro de Comédia, de Franco Zampari. A influência dessa instituição desdobrar-se-ia, nos anos subseqüentes, pelo menos até 1967 , com a 
criação de inúmeros grupos de atores ou diretores-empresários, boa parte dos quais oriundos do TBC, os chamados filhotes do TBC. No entanto, fundara-se em 1953 o Teatro de Arena, em São Paulo, cuja direção será assumida, a partir de 1956, por Augusto Boal, jovem diretor então recém-egresso de curso nos Estados Unidos, onde convivera especialmente com a dramaturgia de Arthur Miller. A partir de 1958, desenvolve aquele grupo os Seminários de Dramaturgia, de que emergiriam, ao final da década e, em especial nos primeiros anos da década seguinte, dramaturgos como Gianfrancesco Guarnieri (Eles não usam black-tie; 1958), Oduvaldo Viana Filho, o Vianinha (Chapetuba Futebol Clube;1958), Bilbao, via Copacabana (Augusto Boal; 1958) e Edy Lima (A farsa da esposa perfeita; 1958). Esses dramaturgos integrar-se-iam, logo depois, ao CPC da UNE, somando-se a Paulo Pontes, desenvolvendo uma obra de intensa denúncia ideológica, de modo que se tornarão os nomes referenciais de toda a dramaturgia brasileira ao longo das duas próximas décadas, ainda que alguns deles tenham experimentado o exílio, como Augusto Boal, ou terminado por se adaptarem à televisão, como Guarnieri, Dias Gomes, Vianinha ou Paulo Pontes, que entende ser a televisão, apesar de tudo, um veículo essencialmente democrático; pode ser ligado por qualquer um.. O grande tema é o que interessa à maioria da população, o que não quer dizer que existe contradição entre qualidade e televisão, mas sim entre a TV e a linguagem aristocráti$\mathrm{ca}^{30}$

Criara-se, assim, a nova dramaturgia televisiva, que resultará nos casos especiais e nas séries brasileiras.

O Teatro de Arena inovou não apenas na dramaturgia, tocando em temas essencialmente vinculados à realidade brasileira, quanto buscou criar novas linguagens e formas de espetáculo, surgindo as experiências da série Arena conta..., a partir da exitosa experiência de um show poético-musical, Opinião, que reuniu dramaturgos, cantores de $\mathrm{mpb}$ e intelectuais brasileiros de renome na época (dezembro de 1964), de um lado, e dos caminhos abertos pelos espetáculos do CPC da UNE, especialmente aqueles que se valiam da música popular, para repassar os seus recados à população, sobretudo a dos estudantes, resultando em experiências como o disco O povo canta, de 1962. Opinião teve a participação de Zé Kéti, João do Vale e da cantora Nara Leão, que se tornaria a musa da bossa nova, interpretando textos de Oduvaldo Viana Filho, Arnaldo Costa e Paulo Pontes, dentre outros.

O TBC, confrontado com sua tradição, reage, produzindo, em 1964, Vereda da salvação, de Jorge Andrade, mais tarde o principal dramaturgo brasileiro contemporâneo, ao lado de Nelson Rodrigues que, enquanto isso, prosseguia sua carreira de obras provocativas, quase sempre proibidas pela censura ou fortemente prejudicadas por cortes absurdos em seu texto.

A tendência de reunir música e dramaturgia chegaria ao auge com o sucesso inesperado, primeiro fora do país, num festival de teatro em Nancy, França, e depois no próprio Brasil, de um espetáculo chamado Morte e vida Severina, que se baseava num texto de João Cabral de Melo Neto, que recebera músicas do então compositorrevelação, Chico Buarque de Hollanda. Era 1965 e a peça, dirigida por Silney Siqueira, tornar-se-ia rapidamente um referencial porque, ao mesmo tempo em que ratificava a denúncia contra as mazelas sociais brasileiras, encontrava uma forma inovadora e atrativa para comunicar-se com o público, fugindo, ao mesmo tempo, do maniqueísmo tão característico das esquerdas, segundo avaliação de Paulo Francis. ${ }^{31}$ A experiência geraria um ciclo de espetáculos que, somados à série já mencionada dos Arena conta... resultaria em trabalhos como Liberdade, liberdade (1965) e Homem do princípio ao fim (1966), culminando no contraditório Roda Viva do Teatro Oficina, de 1968, com texto e música de Chico Buarque de Hollanda e direção de José Celso Martinez Corrêa, aliás, outra referência do teatro des- 
te período, que oscilou, constantemente, entre o ativismo político-ideológico, com obras como Pequenos burgueses (1963), de Gorki, ou Galileu, Galilei (1968), de Brecht, e o experimentalismo radical da linguagem teatral, com a revelação de $O$ Rei da Vela, texto de Oswald de Andrade, de 1933, estreado em 29 de setembro de 1967, até o contraditório Gracias, Señor, com que o grupo encerraria suas atividades no Brasil, diante do exílio de José Celso. Isso, não sem antes ter revelado as idéias de Artaud e Grotowski e ter trazido ao país o grupo inglês The Living Theater, de Judith Malina e Julian Beck, que enfrentou sucessivas perseguições policiais, sob as mais diversas acusações.

Algum tempo depois, estas experiências seriam retomadas, já em outra perspectiva, por Gianfrancesco Guarnieri, com Castro Alves pede passagem (1970).

Um pouco mais distante destes dois centros - o Arena, no perímetro da Boca do Lixo de São Paulo - e a PUC-SP, onde se produzira a peça de Siqueira, um outro ponto mexeria com o teatro brasileiro da década: era o teatro da atriz e empresária Ruth Escobar que, a partir de 1968, traria ao Brasil diretores de renome, em especial o espanhol Victor Garcia, que realizaria trabalhos experimentais de grande envergadura, buscando espaços alternativos na cidade para as suas encenações, como ocorreu com Cemitério de Automóveis, de José Arrabal (1968), encenado em uma garagem, ou recriando os espaços disponíveis, como aconteceu com O Balcão, de Jean Genet (1969), que obrigou à destruição-reconstrução total do teatro de Ruth Escobar.

Uma quarta referência da criação teatral brasileira, como se viu, era o Grupo Oficina que, tendo iniciado na tradição de um método de encenação revolucionário quando de sua criação, mas já clássico na década de 60, o método Stanislawski, contava com a presença de um dos atores mais completos que o teatro brasileiro já teve, Eugênio Kusnet. Clássicos como Brecht e Gorki constituíam o forte de seu repertório, mas a revelação de $O$ Rei da Vela, de Oswald de Andrade, quebraria a linha de criação até então seguida pelo Oficina, levando o grupo a um experimentalismo radical, resultando em sua dissolução, após profunda contribuição ao nosso teatro, em 1974.

$\mathrm{Na}$ continuidade dessas diferentes e contraditórias tendências, produziram-se espetáculos que, impedidos de falar da situação ditatorial brasileira, inspiravam-se em outros casos internacionais para provocarem nossa reflexão. Assim foi com $\mathrm{O} V i$ gário, de Rolf Hochut (1965), imediatamente proibido pela censura, O Berço do Herói, de Dias Gomes (1968), também proibido, Oh que delícia de guerra, de Adhemar Guerra (1966), Marat-Sade, de Peter Weiss, com direção do mesmo Adhemar Guerra (1967) ou O Interrogatório, ainda de Peter Weiss, sob direção de Celso Nunes (1970), abrindo caminho para a posterior experiência de $M a$ cunaíma, já na década seguinte, sem esquecermos a montagem de $O$ Arquiteto e o Imperador da Assíria, de José Arrabal, dirigido por Ivan de Albuquerque (1970), com que também se concluía a década.

Por outro lado, um sem-número de dramaturgos foram sendo revelados a partir do talvez ano mais trágico do teatro brasileiro, na expressão do crítico Yan Michalski, 1968, ${ }^{32}$ auge da crise provocada pelas constantes interdições da censura, produzindo uma dramaturgia cuja principal característica era o enredo baseado em apenas duas personagens, afim de viabilizar as produções, aprofundando, metaforicamente, a condição ditatorial do país. Foram os casos de Antonio Bivar (Abre a janela, Cordélia Brasil, e deixa entrar o sol da manhã, 1968), José Vicente (O Assalto, 1969), Leilah Assunção (Fala baixo senão eu grito, 1969), Consuelo de Castro (À flor da pele, 1969), Isabel Câmara (As moças, 1969) e, muito especialmente, Plínio Marcos, com Jornada de um imbecil até o entendimento (1968), a que se seguiriam, apesar das proibições, Navalha na carne, Quando as máquinas param, Barrela, Dois perdidos numa noite suja, etc. Plínio Marcos tor- 
nar-se-ia, até o final da década de 80, numa espécie de pedra no sapato da ditadura: proibido de ter peças representadas, tornou-se jornalista. Proibido de atuar na revista Veja, mediante ameaças do corte de verbas publicitárias governamentais, passou a freqüentar os bares do Bexiga e Bela Vista, vendendo textos na forma de edições de cordel, dando entrevistas e publicando suas peças por uma editora paulista, num circuito alternativo que se desdobrava pelas universidades, com os livros passando de mão em mão. Continuariam, também, os dramaturgos do Arena, em especial Vianinha, a produzir seus textos, como $A$ longa noite de Cristal (1970) e muito especialmente Corpo a Corpo, do mesmo ano, vencedor de um concurso nacional de dramaturgia, imediatamente proibido, mais tarde, quando encenado, considerado como a melhor metáfora das contradições das diferentes gerações daquele período.

O período que se seguiria, na década de 70 , seria marcado pela reorganização das entidades representativas da categoria, com o surgimento da ACET, reunindo produtores teatrais cariocas, a FENATA, reaproximando realizadores do teatro amador, e a indicação de Orlando Miranda para a direção do Serviço Nacional de Teatro.

Cinema - as contradições no segmento cinematográfico são ainda mais evidentes. Na década de 50, ao lado das produções das chamadas chanchadas da Atlântida, que popularizavam e divulgavam conjuntos musicais brasileiros, como o Trio Irakitan, ou intérpretes oriundos especialmente do teatro de revistas, como Grande Othelo, Dercy Gonçalves, Zezé de Macedo e Oscarito, dentre tantos, buscava-se um projeto mais conseqüente para uma cinematografia nacional, com a criação dos Estúdios Vera Cruz (1950). Para tanto, trouxera-se um conjunto de realizadores italianos, dentre os quais o já citado Franco Zampari, Vitorio Gassman e Ruggero Jacobi, a que se somou o brasileiro Alberto Cavalcanti, já consagrado internacionalmente a partir de seu tra- balho desenvolvido na Inglaterra. O projeto, contudo, apesar de ter produzido algumas obras de referência em nossa cinematografia, naufragaria em torno de 1957, com a debandada dos integrantes da experiência.

O CPC da UNE concretizaria, em 1962, uma experiência curiosa, o filme de longa-metragem 5 vezes favela, composto por cinco diferentes episódios (média metragens) assinados por cinco diferentes realizadores. Um ano antes, Glauber Rocha filmara Barravento, sendo do mesmo ano Os cafagestes de Ruy Guerra, e Arraial do Cabo, de Paulo César Sarraceni, um dos diretores de 5 vezes favela. $\mathrm{O}$ resultado entusiasmaria os jovens realizadores, sobretudo centralizados no Rio de Janeiro ( ao contrário do teatro, cuja maior produção naquela década esteve situada em São Paulo), e sob o slogan "Uma idéia na cabeça e uma câmera na mão" eles dariam início ao que se chamaria de cinema novo brasileiro, sob a inspiração de uma Estética da fome, na acepção de Glauber Rocha (1965). Jovens universitários, leitores dos Cahiers du Cinéma francês, fortemente influenciados por Jean-Luc Godard, dentre outros realizadores, eles buscariam fazer um cinema de denúncia social mas com uma experimentação tão radical de linguagem, que este cinema acabaria absolutamente afastado do público sobre o qual falava, mas com o qual não estabeleceria diálogo: o povo brasileiro, em especial seus segmentos populares. Houve exceções, como o Vidas secas de Nelson Pereira dos Santos (1963), o Deus e o diabo na terra do sol (1964) ou Terra em transe (1967), ambos de Glauber Rocha, que se tornariam referenciais do movimento. Mas o cinema novo foi-se isolando cada vez mais, de sorte que, na metade da década seguinte, era praticamente inevitável sua dissolução em outras estéticas, sobretudo após a morte de Glauber Rocha.

Houve, contudo, algumas experiências significativas, como a produção alternativa de $A$ margem, de Ozualdo Candeias (1967), ou o chamado ciclo da boca-do-lixo, a 
partir de $O$ bandido da luz vermelha, de Rogério Sganzerla (1968), que buscariam uma estética mais condizente com a experiência populista que, por exemplo, programas televisivos como o de Chacrinha trazia aos vídeos de todos os brasileiros, semanalmente.

O AI-5 de dezembro de 1968, contudo, aguçou uma outra tendência, igualmente contraditória tanto em seus produtos quanto em sua avaliação histórica posterior: a pornochanchada. Tratava-se de filmes que sugeriam uma eroticidade que, de fato, não traziam. Pelo contrário, muitas vezes, apelavam a um mau gosto lamentável. Mas ao longo de quase uma década, apesar de seu falso moralismo, mantiveram a indústria cinematográfica brasileira em funcionamento, vindo a experimentar um certo requinte do gênero, por exemplo, com uma série de filmes que, a partir de Os paqueras, de Reginaldo Farias (1969), passam a ser então produzidos. A reformulação da EMBRAFILME - Empresa Brasileira de Filmes, no âmbito do I PNC - Plano Nacional de Cultura, em 1972, permite um melhor planejamento de produção, numa simbiose entre a busca de legitimação do regime autoritário e uma certa flexibilidade de produção, resultando, ainda uma vez, em produtos contraditórios, de um lado, com o ciclo dos filmes históricos, cuja partida se dá com a produção de Independência ou Morte, de 1972, comemorativo ao sesquicentário da independência brasileira, dirigido por Osvaldo Massaini, e, de outro, a uma série de obras que começariam, gradualmente, a abrir-se para uma verdadeira indústria cinematográfica brasileira, e cujo processo seria interrompido na gestão Collor de Melo, para ser retomada na de Fernando Henrique Cardoso. A EMBRAFILME vai se colocar contra o esteticismo e o filme ideológico para poder ocupar o mercado ${ }^{33}$.

Artes plásticas - também este segmento experimentará a permanente contradição em nosso país. Observe-se que, até a década de 60 , não se pode falar em mercado de artes no país, em sentido estrito. Os marchands haviam começado atividades na década anterior, mas de maneira isolada e sem continuidade, sobretudo em centros como o Rio de Janeiro e São Paulo. ${ }^{34}$ Algumas galerias abriram suas portas, igualmente, na década anterior. Será apenas no decorrer dos anos 60, contudo, que a atividade do mercado de artes plásticas implantar-se-á efetivamente no Brasil.

Desde 1951, com o surgimento da Bienal Internacional de São Paulo, o modernismo chegara às artes plásticas entre nós. Mas não se refletia ainda no mercado, apesar dos investimentos feitos pelo MASPMuseu de Arte de São Paulo, idealizado por Assis Chateaubriand, e que investia fortemente na aquisição de obras do impressionismo europeu e do modernismo brasileiro.

As premiações concedidas pela Bienal trazem o artista para o mercado de arte e, consequentemente, a partir de 1961, começam as atividades dos leilões de arte, alternativa encontrada pelos marchands para colocar em evidência um determinado nome, cuja obra acabava valorizada, na maioria dos casos artificialmente, com os diferentes lances que alcançava. Os leilões comerciais ganham espaço em 1965, primeiro em São Paulo, e o boom do mercado surgirá logo na abertura da década seguinte. A maioria das galerias comerciais de grande porte, contudo, foram fundadas ainda na década de 60, a partir de 1967, mas enfrentam alguns problemas:

a) o mercado é caótico, porque não há uma única cidade reconhecida como centro cultural do país e atuando como referencial de valorização e reconhecimento de uma obra;

b) não há marchands que empresariem verdadeiramente movimentos de vanguarda, limitando-se a promover o já razoavelmente estabelecido;

c) não há magnatas que tenham empresariado de maneira significativa a aquisição de coleções ou atraído grandes compras ou financiado a produção de determi- 
nados artistas..$^{35}$

Desde 1956, com o manifesto concretista, surgira uma aproximação entre a literatura e as artes plásticas, sobretudo com o desdobramento do movimento em diferentes tendências, destacando-se, por exemplo, as experiências do arquiteto Julio Pla$\mathrm{za}^{36}$ ou dos próprios irmãos Campos, de Décio Pignatari e do manifesto da poesia semiótica de 1964. O figurativismo, tradicionalmente presente na paisagem plástica brasileira, é invadido pelo abstracionismo. As técnicas utilizadas combinam-se diferentemente, inclusive na distribuição geográfica do país: os artistas plásticos mais engajados ideologicamente, situados, por exemplo, no sul, preferem as técnicas mais tradicionais da gravura e da escultura, enquanto que os experimentalismos formalistas do centro do país vão optar pela pintura, utilizando novos materiais então lançados no mercado, ou desenvolvendo experiências com objetos, ${ }^{37}$ respondendo, de certo modo, a incentivos que as bolsas de estudo de instituições norte-americanas, em especial a Fullbright, colocavam a sua disposição.

Entre 1965 e 1966, o teatro Opinião patrocina duas grandes exposições no Museu de Arte Moderna do Rio de Janeiro, que podem ser lidas enquanto balizadoras das novas tendências. Em 1967 ocorre a exposição Nova Objetividade Brasileira, ainda no MAM carioca, antecedida pela experiência dos parangolés de Hélio Oiticica, influenciado pelo construtivismo e o dadaísmo, no que então se denominou de neoconcretis$m o^{38}$, alcançando uma síntese das diferentes tendências no desdobramento de seu trabalho.

Para Rubens Gershman, um dos principais ativistas de então, o período entre 1964 e 1968 foi o da "utopia absoluta". ${ }^{39}$ Alternam-se, opõem-se e se complementam, ao mesmo tempo, a pesquisa formal e o conteúdo político-ideológico. ${ }^{40}$ Pode-se considerar que este tensionamento ganha sua maior expressividade na exposição coletiva Opinião 66, onde Hélio Oiticica apre- senta um ambiente baseado no jogo de bilhar.

“O bilhar: mais que mistério vital, que segredo oculta na sua plasticidade, na sua atração aos que aele se dedicam? Nesta obra fica patente o que considero antiarte: a habilidade de cada jogador é o que interessa no jogo em si, mas na totalidade é a ação real do jogo que interessa: desde que esta termine, temporariamente ou de vez, cessa a 'obra' em sua ação - não há pois o propósito esteticista de 'apreciar' o jogo na sua beleza, mas apenas realizá-lo" (depoimento de Hélio Oiticica). ${ }^{41}$

A estas duas figuras, soma-se Mário Pedrosa, crítico de formação marxista que vinha promovendo uma revisão dos valores plásticos, nas linhas até então seguidas por diferentes figuras de nossa cultura, em especial Ferreira Gullar, em obras como Cultura posta em questão (1965) e sobretudo Vanguarda e subdesenvolvimento (1969). Pretendia-se distinguir três níveis de produção e circulação artística, quais sejam, a) a arte do povo: rural e marginal, em que artista e povo se confundem identitariamente; $b$ ) arte popular, em que o artista profissional assume a identidade do povo e fala em seu nome; e c) arte popular revolucionária, em que o artista assume um compromisso real com o povo, falando em sua defesa, valorizando, consequentemente, o conteúdo da obra de arte. ${ }^{42}$

\section{III}

Após o golpe de março de 1964, de certo modo a intelectualidade brasileira se reencontrou na Revista de Civilização Brasileira, que o editor Enio Silveira e o poeta Moacyr Félix passaram a publicar, já a partir daquele mesmo ano, numa primeira fase, que se desenvolverá até 1968, quando do AI-5.

Depois da Marcha da Família, com Deus e pela Liberdade, organizada pelos setores mais reacionários da sociedade brasileira, e do golpe de março de 1964, não se interromperia, de um momento para outro, 
o movimento de análise crítica da sociedade brasileira. Naquele mesmo ano de 1964, e apesar do golpe de estado, publicar-se-ia o livro de Caio Prado Jr. que se tornaria uma espécie de bíblia da esquerda brasileira, A Revolução brasileira. Na seqüência dos anos dos festivais brasileiros de mpb, também surgiriam os festivais internacionais, já com patrocinadores multinacionais, e em maio de 1968 não ocorreriam apenas os grandes debates em torno dos movimentos estudantis em Paris, quanto a invasão da União Soviética à Tcheco-eslováquia, o que retiraria boa parte do discurso da esquerda brasileira.

A Guerra do Vietnã de um lado, com a posterior derrota norte-americana, e o movimento yippie internacional responderiam, por outro lado, à expectativa de maior liberdade e criatividade. A morte do estudante secundarista Edson Luís, no restaurante Calabouço, no Rio de Janeiro, e o movimento que se seguiu, no dia 29 de março de 1968, culminaria na grande marcha dos 100 mil, animada pelo líder estudantil Vladimir Palmeira, em 26 de junho, cujo desdobramento seria a negativa do Congresso Nacional em permitir o processo contra o deputado federal Márcio Moreira Alves, o que serviria de desculpa para o Governo editar o Ato Institucional n. ${ }^{\circ}$ 5, de dezembro de 1968, fechando o Congresso e legitimando, de vez, a intervenção governamental em todos os segmentos políticopartidários brasileiros.

A estratégia isebiana de escamotear as oposições de classe em nome de um genérico conceito de nação estava definitivamente sepultada. Sua incapacidade de levar em conta a orientação em direção à industrialização nacional, mediante investimentos internacionais, adotada pela administração JK, a confusão entre um discurso científico e outro, ideológico, ignorando a dissociação ideológica do Brasil, ${ }^{43}$ fez com que as diferenças ganhassem um foro de legitimidade e uma concretude que culminaria no golpe de 1964, que as esquerdas não souberam nem antever nem evitar.
A reforma universitária iniciada na metade da década de 60, modernizou a universidade brasileira, permitindo a criação dos programas de doutorado. $\mathrm{O}$ intelectual, definitivamente, profissionalizouse. Depois de 1974, com a rápida implantação da indústria cultural no país, não cabia mais aos intelectuais qualquer negativa sobre a existência de instituições como a televisão: a identidade demiúrgica do intelectual brasileiro cedia espaço para o intelectual orgânico que, vinculado a um ou outro segmento social, produziria segundo sua identificação grupal. Surgia, por exemplo, dentre outros tantos exemplos, a chamada imprensa nanica, segundo expressão de João Antonio, tão bem estudada pioneiramente por Sérgio Caparelli. ${ }^{44} \mathrm{O}$ Brasil entrara, definitivamente, na era da indústria cultural e se, durante as décadas de 60 e 70, a imprensa alternativa ocuparia importante espaço, com o surgimento de diversas publicações neste campo, como Opinião, a partir de 1972 e até 1977, o jornal Ex, logo proibido e substituído por Mais um, igualmente proibido, além de inúmeros jornais francamente políticos como o Jornal de Debates (1973) e o Politika (1973), De Fato, de Belo Horizonte (1975), ou o Coojornal, de Porto Alegre (1975), que sofreria constante perseguição policial, tendo inclusive ameaçados seus anunciantes com cortes de verbas de publicidade governamental, ou revistas culturais, como a Argumento, a partir de outubro de 1973, que não passaria do quarto número, a contradição entre um e outro aspecto de nossa imprensa permaneceria. Na verdade, tudo começara com a publicação do Pasquim, a partir de junho de 1969, nova experiência de Millôr Fernandes e um grupo de jornalistas que já haviam, anteriormente, feito a inovação de Pif-Paf $_{\llcorner}$de vida efêmera.

A cultura alternativa ganharia, ainda, publicações especializadas como Versus, de 1976, dando prosseguimento, de certo modo, à eclosão das histórias em quadrinhos que, desde a grande exposição do MASP em 1970, alcançara um status privilegiado em nosso país. Versus possibilitou a 
veiculação, no Brasil, de quadrinhos já clássicos internacionalmente e que, no entanto, ainda eram praticamente desconhecidos em nosso país.

Aliás, no campo da chamada grande imprensa, desde a década de 50, com as fortes mudanças sofridas pelos jornais do centro do país, ${ }^{45}$ surgindo os suplementos culturais como o do Jornal do Brasil, que se tornaria praticamente o órgão oficial do concretismo, as reformas haviam ocorrido de maneira profunda e radical, na década de 60. De 1965 a 1968, desenvolvera-se a experiência pioneira da revista Realidade, a primeira tentativa, depois da morte de $O$ Cruzeiro, de se publicar um veículo com caráter nacional. Realidade somava, à tradição de $O$ Cruzeiro, a perspectiva crítica e a qualidade do texto, distanciando-se do perfil populista da revista dos Associados. Mas o AI-5 de 1968 viria a tornar impossível a sobrevivência de Realidade, logo substituída, pela Editora Abril, por uma outra revista, Veja, que marca, por seu lado, a entrada da grande imprensa nas tiragens massivas e num projeto verdadeiramente nacional de circulação.

Na década de 70, por fim, ocorrerá o surgimento dos jornais alternativos localizados em determinados segmentos populacionais, como os feministas Brasil, mulher e Nós, mulheres de 1975, dentre tantos outros.

Uma das grandes novidades do panorama cultural brasileiro na década de 60 foi a criação, a partir de 1966, do Conselho Federal de Cultura, oficialmente implantado no ano seguinte. ${ }^{46}$ A este projeto, que buscava a integração cultural brasileira em uma única ação abrangente, seguir-se-ia o I PNC - Plano Nacional de Cultura, de 1972, seguido do Programa de Ação Cultural, de 1973. O governo federal, senhor da situação político-administrativa, permitia-se liberar os espaços para a produção cultural, agilizando e patrocinando o fomento cultural, numa perspectiva de mercado capitalista de bens de consumo (p. 237).

O Brasil saltaria dos quatro milhões de jornais diários de 1960 para os 1,2 bilhões de jornais-dia de $1976 .{ }^{47}$ Ocupava um lugar destacado na indústria cultural mundial, eis que em 1975 era o nono mercado mundial de televisão, o quinto mercado mundial do disco e o sexto mercado mundial de publicidade. ${ }^{48}$

O governo federal alcançara sua legitimação através de três iniciativas básicas:

a) incentivo à produção cultural;

b) dinamização dos circuitos de distribuição;

c) consumo de bens culturais. ${ }^{49}$

$\mathrm{Na}$ verdade, "a montagem de bens simbólicos em ritmo industrial nos fornece um modelo de tempo cultural acelerado", segundo bem observa Alfredo Bosi, ${ }^{50}$ que acrescenta: o sempre novo, contudo, nem sempre é original. Na verdade, constituíase neste processo uma nova oposição entre produção industrial e ciclos e enraizamento, de maneira que o novo jamais tinha a oportunidade de aprofundar-se, sendo logo substituído por outro produto, ou seja, jamais se experimentava uma continuidade de processo, mas sim, o constante lançamento de outros produtos que substituíam artificialmente os anteriormente veiculados. Após 1964, produz-se no interior do Brasil todo e qualquer produto cultural, embora o tratamento que lhes é dado esteja muito mais vinculado ao mercado internacional do que ao local, eis que se trata de produtos padronizados e estandardizados segundo modelos universais: os meios de comunicação de massa em geral, e a televisão, em particular, constituem os veículos de uma ação 'pedagógica' a serviço do processo de unificação do mercado material e simbólico, que se traduz pela imposição 'diferencial' da cultura dominante. ${ }^{51}$

A complementaridade do processo é dada pelo próprio governo federal, através de produções como Minerva em ação cultural ou Domingo Mobral, de que resulta um país colorido e tropical, pleno de manifestações folclóricas que podem ser aproximadas e assimiladas pelas produções da indústria cultural, na medida em que não se diferen- 
ciam, para o grande público, os circuitos de sua circulação. ${ }^{52}$

Para muitos, o ano de 1968, marcado pelo AI-5, é o ano de verdadeiro início da década de 60 que se expandiria, assim, pela década seguinte. Neste sentido, é preciso considerar que a década de 50 e seu ufanismo contraditório havia se estendido, efetivamente, ao longo de mais da metade da década seguinte, e que a década de 60, aberta em 1968, seria, sobretudo, a 'época da negação", segundo José Celso Martinez Corrêa. ${ }^{53}$

De fato, os anos 60 serão anos de "virada", como querem alguns ${ }^{54}$. O Brasil não é mais um país subdesenvolvido. $\mathrm{O}$ outdoor ganha cidadania (p.6). O país possui $30 \mathrm{mi}-$ lhões de espectadores de televisão (p. 33) e logo o slogan "este é um país que vai pra frente" torna-se parcialmente realidade ( $p$. 93).

A experiência da primeira grande campanha publicitária de fundo políticopartidário, desenvolvida pela sul-riograndense MPM Propaganda, quando do plebiscito em torno da fórmula parlamentarismo x presidencialismo, no decorrer de 1962, culminando na histórica decisão de 6 de janeiro de 1963, em favor do retorno ao presidencialismo, inaugurara a ostensiva presença das empresas publicitárias no horizonte da opinião pública brasileira. Não é de se surpreender, portanto, que, depois de março de 1964, elas se aliem ao novo governo e auxiliem, de maneira decisiva, a construir o novo perfil do país. Atingia-se, na década de 70, cerca de 500 mil mensagens-dia de propaganda, segundo Celso Japiassu. ${ }^{55}$ Existiam, contudo, problemas a serem ultrapassados, segundo Muniz Sodré:

a) controle central das emissões;

b) existência de um só emissor, mas receptores diferenciados;

c) imobilização dos indivíduos, considerados isoladamente;

d) revolução passiva de costumes e hábitos cotidianos;

e) despolitização social; f) produção televisiva feita exclusivamente por especialistas;

g) controle da televisão exercido exclusivamente por seus proprietários e não pelos receptores. ${ }^{56}$

A década de 60 termina com um balanço extraordinário: 30 milhões de brasileiros economicamente ativos, 12 milhões de cidadãos integrados nacionalmente em rede por televisão, três milhões de cidadãos contribuintes do imposto de renda, 500 mil leitores, tiragens de cinco mil exemplares nas edições dos chamados bestsellers. ${ }^{57}$ Ao longo da década, $24 \%$ do valor total alocado para a publicidade estaria concentrado na televisão, percentual que aumentaria nos anos seguintes, ${ }^{58}$ atingindo $90 \%$ na década seguinte.

A introdução da televisão no continente, aliás, provocara uma retração de mais de metade da circulação de jornais ${ }^{59}$. O grande negócio da televisão expandirase em três lucrativos campos de atividades: a venda de aparelhos, que vão sendo barateados à medida em que sua produção é nacionalizada e se massifica, inclusive depois da introdução da televisão a cores; venda de filmes para veiculação nas diferentes estações; venda dos espaços de publicidade, em especial para o governo.

O balanço da década, não obstante, reserva ainda um panorama de contradições: o Estado crescera, mas não os direitos da sociedade civil. ${ }^{60}$ Contudo, alguns jornalistas como Luís Carlos Maciel preferem lembrar a década dos 60 sob outro prisma: $a$ grande lição que se tentou aprender, nos anos 60, foi a liberdade. Verificou-se o seguinte: o que as pessoas fazem socialmente é pura loucura, um escudo usado como proteção contra a verdadeira natureza da realidade, espontânea e incontrolável. As instituições cristalizam essa proteção, para que ela possa ser utilizada pelas massas. Só pode haver conhecimento de verdade, clareza, quando os escudos são dispensados. Um escudo é útil, como defesa, mas também cobre a visão. A experiênia vital dos 60 foi distorcida, diluída e, finalmente, esquecida nos 
anos seguintes. Os caminhos da liberdade 1958

foram perdidos mais uma vez. ${ }^{61}$

Para Maciel, os anos 70 "são os anos mestres" e os 80 "os anos da diluição". Para nós, os anos 60 continuarão sendo os anos da contradição, quando descobrimos a liberdade e as inúmeras alternativas de vida, mas quando também sofremos a interdição, a proibição e a negação •

\section{Acontecimentos Político-Econômicose Culfurais da década de 60 no Bra- sil e América Latina:}

1948 constituição do TBC/Teatro Brasileiro de Comédia/

S. Paulo

1951

1951 criação $\mathrm{CNPq}$

1961

1968

1968

1975

1950/1957

09/1950

1951

1951

1953

1953

1955

1955

1956

1956

1956

1956

1957

1958

22/02/1958

1958

1958

1958

1958

1959

1959

1959

1960

1960 criação CAPES criação FINEP criação FAPESP reforma universitária abertura da SBPC às ciências humanas Cia. Cinematográfica Vera Cruz TV Tupi, canal 3 (até 1980)/São Paulo

TV Tupi do Rio de Janeiro Bienal de São Paulo/São Paulo

TV Record do Rio de Janeiro fundação do Teatro de Arena /S. Paulo formação da 1a. Liga Camponesa Engenho Galiléia criação da TV na Venezuela criação da TV no Uruguai Augusto Boal assume direção do Arena/SP surgimento do ISEB Instituto Superior de Estudos Brasileiros L/Manifesto da Poesia concreta L/manifesto do grupo Tendência Affonso Avila Belo Horizonte Seminários de Dramaturgia do Arena/SP T/Eles não usam black-tie Gianfrancesco Guarnieri/Arena/São Paulo T/Chapetuba Futebol Clube Oduvaldo Viana Filho/Arena/São Paulo T/Quarto de empregada Roberto Freire/Arena/São Paulo T/Bilbao, via Copacabana Augusto Boal/Arena/São Paulo $\mathrm{T} /$ Gente como a gente
1959(1956?)

T/A farsa da esposa perfeita

Edy Lima/Arena/São Paulo

L/manifesto da poesia neo-concretista

$\mathrm{M} /$ surgimento da bossa nova Revolução Cubana

surgimento do IBAD

Instituto Brasileiro de Ação Democrática, ligado à CIA década de 60

21/04/1960

$17 / 08 / 1961$

25/08/1961

na Conferência Pan-Americana de Punta del Este

I Convenção de Crítica Cinematográfica

surgimento da Aliança para o Progresso renúncia de JQ e imediata posse do

Presidente da Câmara Federal, Ranieri Mazzili

02/09/1961 votação pelo Congresso Nacional do Parlamentarismo $07 / 09 / 1961$

$29 / 11 / 1961$ posse de João Goulart Roberto Freire Arena São Paulo

\section{empréstimos ao Brasil de U\$ 624,400 milhões e doação de U\$ 152,600 milhões}

1961 decreto de JQ obriga percentuais de transmissão
$30 / 05 / 1961$

1961

1961

1961

1961

1961

$12 / 1961$ a $03 / 1964$ de mpb nas emissoras de rádio DECRETO 50.666 cria o CONTEL $\mathrm{L} /$ manifesto do poema práxis Mário Chamie (1962?) / São Paulo C/Barravento/Glauber Rocha $\mathrm{C} /$ os Cafajestes/Ruy Guerra C/Arraial do Cabo/Paulo César Sarraceni surgimento da TV Educativa fundação do CPC Centro de Cultura Popular da UNE 06/07/1962 apresentação da emenda à Constituição pelo Senador Argemiro de Figueiredo que extingue o Parlamentarismo

19623 Cadernos do Violão de Rua/Rio de Janeiro 08/03/1962 aprovação do regimento interno do CPC 08/1962 Lei do Satélite de Comunicações/Kennedy/USA 11/1962 I Conferência de Lavradores e Trabalhadores

1962 Agrícolas Brasileiros/Belo Horizonte $\mathrm{C} / 5$ vezes favela

1962

(filme de episódios financiado pelo CPC/UNE) $\mathrm{MPB} /$ disco O Povo canta (financiado pelo CPC/UNE)

1962 institucionalização do Código Brasileiro de Telecomunicações 1962 acordo técnico grupo Time-Life/TV Globo 1962 1962 $06 / 11 / 1963$ surgimento da ABERT

Jornal de Vanguarda - TV Excelsior /São Paulo votação e aprovação do retorno ao Presidencialismo 
$02 / 1963$

20/03/1963

$31 / 10 / 1963$

1963

1963

1963

1963

$19 / 08 / 1963$

$10-11 / 1963$

1964

$13 / 03 / 1964$

$20 / 03 / 1964$

$31 / 03 / 1964$

20/08/1964

International Communications Satelitte Consortium

1964 C/Deus e o diabo na terra do sol/Glauber Rocha

1964 Ensaio/A Revolução Brasileira/Caio Prado Junior

05/1964 revista Pif-Paf de Millor Fernandes

31/03/1964 T/Os Azeredo mais os Benevides

Oduvaldo Vianna Filho

1964 T/Vereda da Salvação, de Jorge Andrade/ TBC/São Paulo

$12 / 1964$

$01 / 04 / 1964$

1965

$08 / 1965$

1965

1965

1965

1965

1965

26/04/1965 inauguração da TV Globo/Telejornal da Globo

1965 Ensaio: Cultura posta em questão/Ferreira Gullar

1965 Ensaio: Estética da fome/ Glauber Rocha

1965 proibição total de peças como O Vigúrio, O Berço do Herói

1965-1968

1965

1965-1966

1966

1966

1966

1966

1966

1966

T/ Show Opinião/Rio de Janeiro invasão e depredação do ISEB e da UNE, que é incendiada/Rio de Janeiro difusão mundial das pesquisas com LSDa alegria da descoberta da sexualidade Revista REALIDADE/São Paulo C/O desafio/Paulo César Sarraceni

C/São Paulo SA/Luiz Sérgio Person T/Morte e Vida Severina, Silney Siqueira T/Arena conta Zumbi $\mathrm{T} /$ Liberdade, Liberdade T/Arena conta Bahia Revista Civilização Brasileira (1a. fase)/RJ leilões de artes plásticas/São Paulo $\mathrm{AP} /$ exposições Opinião/MAM/Rio de Janeiro influência do Living Theater influência de Artaud e Grotowski C/O Desafio/Paulo César Sarraceni T/Onde canta o sabiá/Gastão Tojeiro/Paulo Affonso Grisolli $\mathrm{T} /$ Os Inimigos/Oficina $\mathrm{T} /$ Homem do princípio ao fim
1966

1966

$1966 / 1967$

1966

1966

1967

1967

1967

1967

1967

1967 29/09/1967

1967

1967

1967

1967

1967

1967

1967

1967

1967

1967

1967

1967

1967

1967

1967

1968

1968

1968/1970

$04 / 01 / 1968$

$15 / 01 / 1968$

$05 / 1968$

Relacões Públicas da Presidência da República

TV/festivais de mpb/III Festival TV Record morte de Assis Chateaubriand/Diários Associados implantação do satélite doméstico brasileiro de telecomunicações

C/O Bandido da Luz Vermelha/Rogério Sganzerla

C/O Bravo guerreiro/Gustavo Dahl início de pesados investimentos pelos USA em comunicações na America do Sul Lei de Censura

Guerra do Vietnã/ataque da URSS à Tchecoeslováquia/ rebeldia dos jovens em Paris

28 /03/1968 morte do estudante Edson Luís no ataque ao Restaurante Calabouço/RJ

26/06/1968 passeata dos $100 \mathrm{mil} /$ surgimento de Vladimir Palmeira $10 / 1968$

$12 / 1968$

$13 / 12 / 1968$

1968

1968

1968

1968 congresso da UNE em Ibiúna negativa do Congresso Nacional em cassar o deputado Mário Moreira Alves Ato Institucional n. 5 0 ano mais trágico do teatro brasileiro T/Roda Viva/Oficina/Chico Buarque/ José Celso L e M - surgimento do Tropicalismo T - Cemitério de Automóveis - Victor Garcia 
/Arrabal/ Ruth Escobar/SP

1968

$\mathrm{T} /$ Eu sou vida, eu não sou morte/redescoberta de

Qorpo Santo

1968

$\mathrm{T} /$ Jornada de um imbecil até o entendimento/Plínio

Marcos

1968 T/Feira Paulista de Opinião/só com peças proibidas

1968

1968

1968

1969

1969

1969

1969

1969 T/Fala baixo senão eu grito/ Leilah Assunção/S. Paulo

1969 T/À flor da pele/Consuelo de Castro/São Paulo

1969

1969

1969

T/As moças/Isabel Câmara/São Paulo

T/O Balcão/Victor Garcia/Ruth Escobar/São Paulo

Ensaio/Vanguarda e subdesenvolvimento/Ferreira

Gullar

1969

$26 / 06 / 1969$

1969

1969

1969

01/09/1969

1970

1970

1970

1970

1970

1970

1970

1970

1970

1970

1970

$1970 / 1$

1970

1970

1972

1970

1972 organização profissional da classe teatral surgimento do PASQUIM nacionalização da TV Globo surgimento do movimento yippie mundial chegada do vídeo-tape no Brasil

Jornal Nacional da TV Globo/Rio de Janeiro população nacional economicamente ativa: 30 milhões; 500 mil leitores 90\% dos recursos de publicidade estão dirigidos para a TV surgimento do BONDINHO Titulares da Notícia/TV Bandeirantes/SP incremento qualitativo da telenovela na Globo: TV/Irmãos Coragem/TV Globo/Rio de Janeiro transmissão internacional da Copa do Mundo utilização do out odor para publicidade valorização do filme histórico

T/A longa noite de Cristal/Oduvaldo Vianna Filho T/O Interrogatório/Peter Weiss/ Celso Nunes T/O Arquiteto e o Imperador da Assíria /Ivan de Albuquerque/ Rubens Corrêa e José Wilker/R. Janeiro T/A resistível ascensão de Arturo Ui/Brecht/ despedida do ARENA teatro-jornal do Arena/prisão de A. Boal boom mercado de artes/São Paulo/R. Janeiro

T/Castro Alves pede passagem/ Gianfrancesco Guarnieri criação do Conselho Nacional de Telecomunicações T/Corpo a Corpo/Oduvaldo Vianna Filho C/Independência ou Morte/Osvaldo Massaini
$1972 / 7$

1972

1973

1973

1973

1973

$10 / 1973$

1974

1974

1974

1974

1975

1975

1975

1975

1975

1975

1975

1976

1977

1977 surgimento do EM TEMPO/Os Cafajestes/Ruy Guerra

\section{Notas}

1 COUTO E SILVA, Golbery - Conjuntura politica nacional - 0 Poder Executivo \& Geopolitica do Brasil, Rio de Janeiro, José Olympio. 1981.

2 FURTADO, Celso - "Que somos?" , São Paulo, Folha de São Paulo. Ilustrada. 28 de abril de 1984, p. 44. Revisto e retrabalhado em Cultura e desenvolvimento em época de crise. Rio de Janeiro, Paz e Terra. 1984, p.17 e ss.

3 MOTA, Carlos Guilherme - Ideologia da cultura brasileira (1933-1974), São Paulo, Ática. 1978, p.27 e ss.

4 FADUL, Anamaria - "Políticas culturais e processo político brasileiro" in MELO, José Marques de - Comunicação e transição democrática, Porto Alegre, Mercado Aberto. 1985, p.180 e ss.

5 PÉCAUT, Daniel - Os intelectuais e a politica no Brasil, São Paulo, Ática. 1990, p. 107 e ss.

6 ORTIZ, Renato - Cultura brasileira \& identidade nacional, São Paulo, Brasiliense.1985, p. 46-47. 
7 SODRÉ, Nelson Werneck - A verdade sobre o ISEB, Rio de Janeiro, Avenir.1978 e TOLEDO, Caio Navarro de Toledo - ISEB: Fábrica de ideologias, São Paulo, Ática. 1977.

8 OLIVEN, Ruben George - "Industrialização, urbanização e meios de comunicação de massa" in MELO, José Marques de - Op. cit., p. 30 e ss.

9 PÉCAUT, Daniel - op. cit., p. 105, apud WEFFORT, Francisco - Origens do sindicalismo populista no Brasil: a conjuntura do após-guerra, São Paulo, USP. 1972. Tese de Doutorado, mimeo.

10 DREIFUSS, René Armand - 1964: A conquista do Estado, Petrópolis, Vozes. 1981 e CARONE, Edgard - A República liberal - II - evolução política (1945-1964), São Paulo, DIFEL 1985, p.185.

11 CHAUÍ, Marilena - O Nacional e o popular na cultura brasileira - Seminários, São Paulo, Brasiliense. 1983, p.96/7 e ss.

12 Idem, ibidem, ps. 73/4.

13 Idem, ibidem, p. 86. Ver, também, BERLINCK, Manoel T. - O Centro Popular de Cultura da UNE, Campinas, Papirus. 1984.

14 FREITAS Filho, Armando; HOLLANDA, Heloísa Buarque de; et GONÇALVES, Marcos Augusto - Anos 70 Literatura, Rio de Janeiro, Europa.1979/1980.

15 BOSI, Alfredo et allii - Conjuntura Nacional - III Ciclo de debates do Teatro Casa Grande, Petrópolis, Vozes. 1979, p.211 e ss.

16 SODRÉ, Muniz - "O mercado de bens culturais" in MICELI, Sérgio (Org.) - Estado e cultura no Brasil, São Paulo, DIFEL.1984, p. 138 e ss.

17 RÜDIGER, Francisco Ricardo - "Publicidade no Brasil pós-64: função econômica e projeto hegemônico" in MELO, José Marques - op. cit. , p. 36 e ss.

18 CAPARELLI, Sérgio - Comunicação de massa sem massa, São Paulo, Cortez.1980 e CAPARELLI, Sérgio - Televisão e capitalismo no Brasil, Porto Alegre, L\&PM. 1982.

1915 ANOS DE HISTÓRIA, Rio de Janeiro, Rede Globo de Televisão.1984, p. 347.
20 SCHILLER, Herbert - 0 império norte-americano das comunicações, Petrópolis, Vozes. 1976, p.145 e ss.

21 A primeira transmissão a cores ocorreu oficialmente no Brasil no dia 10 de fevereiro de 1972, com a inauguração da Festa da Uva, em Caxias do Sul, Rio Grande do Sul, pela Tv Globo.

22 KEHL, Maria Rita - Anos 70 - Televisão, Rio de Janeiro, Europa.1979/1980.

23 MESQUITA, Humberto - Tupi: A greve da fome, São Paulo, Cortez.1982, em especial p.185 e ss.

24 ORTIZ, Renato - op. cit., p. 83.

25 CANDIDO, Antonio - Literatura e sociedade, São Paulo. Cia. Editora Nacional. 1980.

26 Para uma boa análise desta produção, ver SANT'ANNA, Affonso Romano de - Música popular e moderna poesia brasileira, Petrópolis, Vozes.1980.

27 HOHLFELDT, Antonio - "Relações entre jornalismo e literatura na década dos 70" in KOHUT, Karl (Org.) Palavra e poder - Os intelectuais na sociedade brasileira, Frankfurt am Main, Vervuert Verlag. 1991, p. 125 e ss.

28 SUSSEKIND, Flora - Tal Brasil, qual romance?, Rio de Janeiro, Achiamé. 1984.

29 CANDIDO,Antonio - Literatura e subdesenvolvimento in Revista Argumento, Rio de Janeiro, Paz e Terra, Ano 1, N. 1, p. 7 e ss.

30 KEHL, Maria Rita - "Um só povo, uma só cabeça, uma só nação" in CARVALHO, Elisabeth; KEHL, Maria Rita; et RIBEIRO, Santuza Naves (Org.) - Anos 70 - Televisĩa, Rio de Janeiro, Europa.1979/1980, ps. 20/1.

31 FRANCIS, Paulo - "Um balaio de nacionalismo e experimentalismo", São Paulo, Revista Visão. Fevereiro de 1970. Citado por HOLLANDA, Heloísa Buarque de et GONÇALVES, Marcos Augusto - "Política e literatura: a ficção da realidade brasileira" in FREITAS FILHO, Armando et allii - Anos 70 - Literatura, op. cit., p.7.

32 MICHALSKI, Yan - O teatro sob pressão, Rio de Janeiro, Jorge Zahar.1985, p. 33. 
33 ORTIZ, Renato, op. cit., p. 113.

34 DURAND, José Carlos - "Expansão do mercado de arte em São Paulo" in MICELI, Sérgio - op. cit., p. 173 e ss.

35 Idem, ibidem, p. 202 e ss.

36 PLAZA, Julio e CAMPOS, Augusto - Caixa preta, São Paulo, Invenção. 1975.

37 AYALA, Walmir - Arte gaúcha 74, catálogo da exposição de igual título, Rio de Janeiro. MEC.1974. Ver também, HOHLFELDT, Antonio - "Figuras e abstração nas artes plásticas gaúchas" in Mudanças, quatro ensaios de sociologia da arte, Caixas do Sul/Porto Alegre, UCS/EST. 1977, p. 53 e ss. Deve-se consultar, igualmente, PONTUAL, Roberto "50 anos de arte brasileira", texto introdutório ao catálogo da exposição Arte/ Brasil/hoje - 50 anos depois, São Paulo, Galeria Collectio 1973.

38 ZILIO, Carlos - 0 nacional e o popular na cultura brasileira Artes plásticas, São Paulo, Brasiliense. 1982, p. 26 e ss.

39 HOLLANDA, Heloísa Buarque de et GONÇALVES, Marcos A. - Cultura e participação nos anos 60, São Paulo, Brasiliense. 1982, p. 89.

40 ZILIO, Carlos - op. cit., p. 33.

41 ZILIO, Carlos - idem, ibidem, p. 53.

42 CHAUÍ, Marilena - O Nacional e o popular na cultura brasileira - Seminários, op. cit., p. 126 e ss., p. 126.

43 PÉCAUT, Daniel - op. cit.; p. 132.

44 Caparelli, Sérgio - Comunicação de massa sem massa, op. cit. e HOHLFELDT, Antonio - op. cit. in nota 22.

45 SILVA, Carlos Eduardo Lins da - 0 adiantado da hora, São Paulo, Summus. 1991. Ver, também, ABREU, Alzira Alves de (Org.) - Imprensa em transição, Rio de Janeiro, Fundação Getúlio Vargas.1996.

46 MICELI, Sérgio - op. cit., p. 234 e ss.

47 ORTIZ, Renato - op. cit., p. 83.

48 Idem, ibidem, p. 84.
49 Idem, ibidem, p. 115.

50 BOSI, Alfredo - Cultura brasileira, São Paulo, Ática. 1987, p.9.

51 MICELI, Sérgio - A noite da madrinha, São Paulo, Perspectiva. 1972, p. 218.

52 OLIVEN, Ruben George - op. cit., p. 82.

53 FREITAS FILHO, Armando et allii - op. cit., p. 21.

54 CARVALHO, Elisabeth et allii - op. cit. p. 12.

55 JAPIASSU, Celso - I Ciclo de debates do teatro Casa Grande, Rio de Janeiro, Inúbia. 1976, p. 209, II.

56 SODRÉ, Muniz - I Ciclo de debates do teatro Casa Grande, op. cit., ps. 122, I e II, e p. 123, I.

57 CABRAL, Reinaldo - Literatura e poder pós-64, Rio de Janeiro, Opção. 1977, p.17.

58 CAPARELLI, Sérgio - Comunicação de massa sem massa, op. cit., p. 10.

59 CAPARELLI, Sérgio - Televisão e capitalismo no Brasil, op. cit., p.152.

60 CARDOSO, Ruth - Sociedade civil e meios de comunicação no Brasil in MELO, José Marques (Org.)- op. cit., p. 118 e ss.

61 MACIEL, Luís Carlos - Anos 60, Porto Alegre, L \& PM. 1987, p. 117. 